\title{
Prevalence of Willis-Ekbom Disease/Restless Legs Syndrome During Pregnancy: A Review
}

\author{
Hensley $\mathrm{JG}^{*}$ and Shamim-Uzzaman QA
}

University of Colorado, Education 2 North 13120 E. 19th Ave., Aurora, CO 80045, USA

\begin{abstract}
Willis-Ekbom Disease/Restless Legs Syndrome (WED/RLS), a disorder frequently unrecognized and under diagnosed during pregnancy, may affect one out of every three women in this population. Symptoms can lead to disrupted sleep and adversely affect daytime alertness and performance. The exact prevalence of WED/RLS during pregnancy is unknown, largely due to lack of standardization for assessment of the disorder. We present a review of articles examining this, so clinicians can appreciate assessment and treatment of the up to $34 \%$ of pregnant women who may suffer from $\mathrm{WED} / \mathrm{RLS}$ and its consequences.
\end{abstract}

Keywords: Willis-Ekbom Disease, Restless Legs Syndrome, prevalence, pregnancy and postpartum.

\section{INTRODUCTION}

Restless Legs Syndrome (RLS), now known as WillisEkbom Disease (WED), in the U.S., is the "most common disorder you have ever heard of" $[1,2]$. It is a sensorimotor phenomenon diagnosed clinically by the following four essential criteria and not explained by any other disorder:

1. An urge to move the legs (or other parts of the body) usually accompanied or caused by uncomfortable or unpleasant sensations in the legs.

2. The urge to move or unpleasant sensations begin or worsen during periods of rest or inactivity such as lying or sitting.

3. The urge to move or unpleasant sensations are partially or totally relieved by movement, such as walking or stretching, at least as long as the activity continues.

4. The urge to move or unpleasant sensations follow a circadian pattern, usually worse in the evening or night than during the day or only occur in the evening or night [3].

Clinical features that support the diagnosis of WED/RLS include a positive family history, presence of periodic limb movements (PLMs) during sleep and/or wakefulness, and symptomatic improvement with dopaminergic therapy.

Periodic limb movements (PLMs) typically occur as periodic, repetitive episodes characterized by extension of the big toe and flexion of the leg, especially during sleep. Initially, more than five PLMs per hour during total sleep time as measured on a polysomnographic study were considered abnormal. However, in the second version of the

*Address correspondence to this author at the University of Colorado, Education 2 North 13120 E. 19th Ave., Aurora, CO 80045, USA;

Tel: 303/724-8533; Fax: 303/724-8559;

E-mail: Jennifer.hensley@ucdenver.edu
International Classification of Sleep Disorders (2005) this number was increased to 15 PLMs per hour $[4,5]$. Older studies have shown that up to $80 \%$ of WED/RLS sufferers have PLMs which are associated with arousal from sleep [6]. Arousals disrupt sleep and can adversely impact daytime alertness and performance.

Over the past two decades, much has been learned about WED/RLS, its proposed etiologies, its disruption of sleep, and its adverse effects on daytime functioning and quality of life. However, little is known about WED/RLS during pregnancy. In this review, we attempt to offer a history of WED/RLS, discuss its prevalence during pregnancy, describe its proposed etiologies, and, finally, offer potential treatment options, specifically during pregnancy.

\section{HISTORY OF RESTLESS LEGS SYNDROME}

Symptoms suggestive of WED/RLS have been described as far back as the late $17^{\text {th }}$ century. The oldest account, in Sir Thomas Willis' The London Practice of Physick, described difficulty in falling asleep because of "leapings and contractions of the tendons, and so great a restlessness and tossing of their members ensue, that the diseased are no more able to sleep than if they were in a place of greatest torture" [7]. A century later, Francois Boissier de Sauvages de La Croix described a similar condition which was seen "frequently...in clinical practice" involving "everyday women, and especially men...who when the evening comes, cannot keep their legs still for a single minute because of the restlessness they feel in then." He termed this condition "Anxietas Tibiarum (Anxiety of the Legs)" [8], a term which was also used by Wittmaack almost a hundred years later [9].

Before the mid-1900s, WED/RLS symptoms were thought to be functional impairments related to hysteria, neurosis, or neurasthenia (nervous exhaustion) [9-12]. Oppenheim was the first to suggest a hereditary etiology [12]. In 1940, Mussio-Fourier and Kawak first reported symptoms of "pruritis, uticaria and paresthesias" in family 
members, which worsened during pregnancy; they refuted the classification of these symptoms as a neurosis [13].

It was not until 1945 that Swedish neurologist Karl Axel Ekbom coined the term Restless Legs Syndrome and described the full spectrum of the disorder, particularly in pregnant women [14]. However, until this publication, the misnomer "anxiety of the legs" has continued to plague RLS as being a form of hysteria, and has often led to trivializing the clinical impact of the condition. Therefore, in 2011, the Restless Legs Syndrome Foundation in the US approved a name change to Willis-Ekbom Disease, in part, to reflect the severity of the disease, but also to acknowledge Willis' and Ekbom's contributions to understanding the disease [2].

\section{PREVALENCE OF WED/RLS DURING PREGNANCY}

The prevalence of WED/RLS varies in the general population from $5-15 \%$, and has been shown to be twice as common in women as men [15]. To evaluate the prevalence of WED/RLS during pregnancy, we conducted Pub Med and World of Science searches using the keywords "restless legs syndrome" and "pregnancy". This yielded 131 articles in Pub Med. Of these, 16 were peer-reviewed articles specifically dealing with the prevalence of WED/RLS during pregnancy and were written in the English language; these 16 articles, spanning 1945 - 2012, were included in this review (Table 1) [16-31].

Several different methodologies were used to determine the presence of WED/RLS in these pregnant populations. Six studies had participants who completed self-administered questionnaires [17-20, 25-27], another seven conducted face to face interviews [16, 21-24, 26, 29, 31], and three studies did not specify how data was collected [28, 30, 31].

Five studies began retrospective data collection during the postpartum period [18, 22, 24, 26, 29]. Three studies collected data in the third trimester $[17,20,29]$, one of which included a follow-up at four weeks postpartum [29]. One study examined the first and third trimesters [19], while another examined the second and third trimesters [23]. Four studies collected data during all three trimesters $[21,25,27,28]$. Two studies did not specify when data was collected $[30,31]$.

All four of the 1995 International Restless Legs Syndrome Group (IRLSSG) criteria for the diagnosis of WED/RLS were used in one study [26, 32], while two studies used one criterion [27, 28, 32]. In 2003, after revision of the IRLSSG criteria for the diagnosis of WED/RLS, ten studies used all four criteria [16, 17-25, 32]. The most recent study by Chen et al. (2012) used all four criteria. Women were interviewed face to face after admission to the hospital. To determine severity, the Johns Hopkins RLS Severity Scale was administered. Women were telephoned three months postpartum. For consistency, one neurologist reviewed all questionnaires [16].

In 1945, Karl Ekbom performed the first large epidemiological study of WED/RLS in pregnancy and found a prevalence rate of $11.3 \%$ among 486 pregnant patients [31]. In 1988, Goodman et al reported a prevalence of $19 \%$ in 500 singleton pregnancies at 32-34 weeks gestational age [29]. Symptoms began to resolve about 4 weeks prior to delivery, and all but 3 of the 97 women with WED/RLS had resolution of their symptoms back to baseline 4 weeks after delivery. Thirteen of forty-three women (30\%) had similar symptoms in a previous pregnancy.

Manconi et al. (2004) were the first to use the 1995 IRLSSG criteria to diagnose WED/RLS during pregnancy. Face to face interviews were conducted after delivery, and at one, three and six months postpartum. They reported a prevalence of $26.6 \%$ in 606 pregnant women: $16.6 \%$ had new-onset WED/RLS during the pregnancy and $9.9 \%$ had pre-existing WED/RLS symptoms prior to the pregnancy. Of the161 women with WED/RLS, $29 \%$ had a positive family history in a first-degree relative, and $36 \%$ of multiparous women had similar symptoms in at least one previous pregnancy. WED/RLS symptoms were associated with prolonged sleep onset latencies, decreased total sleep time, and excessive daytime sleepiness. Furthermore, peak prevalence of RLS in the third trimester was confirmed, specifically in the $7^{\text {th }}$ and $8^{\text {th }}$ months, predominantly in newonset WED/RLS cases, with a significant resolution of symptoms after delivery to a prevalence of $6.8 \%$ one-month post-partum. The prevalence remained at 5-6\% six months later [26].

Prevalence as high as $34 \%$ was reported out in Norway by Uglane et al. (2011), with complete resolution of symptoms two to three days after delivery in $97 \%$ of patients who had new-onset RLS during the pregnancy [18]. This study was done using self-administered questionnaires within three days postpartum.

The two largest studies have come out of Japan. In contrast to a prevalence of ten percent in the general population [33, 34], Suzuki et al. [27] reported a $19.9 \%$ prevalence of RLS during pregnancy in 2003. They evaluated WED/RLS symptoms in 16,528 pregnant women based on a single question, "Is your sleep interrupted by a sensation of 'insects running across the skin' or 'hot flashes inside your legs after you go to bed at night'?" In 2008, Harano et al. [25] evaluated 19,441 women. They used all four 2003 IRLSSG diagnostic criteria and found an overall prevalence of $2.9 \%$, although the incidence increased from the first to the third trimester. The difference between $19.9 \%$ and $2.9 \%$ in 2003 and 2008 respectively, could be explained by Suzuki et al asking only one of the four essential IRLSSG criteria for diagnosis. Both groups of researchers used questionnaires sent to participating clinics for selfadministration by women waiting for appointments. Without proper instruction on how best to complete the questionnaire, the number of women affected by WED/RLS in the Harano et al study could be underrepresented. Chen et al. [16] found a prevalence of $10.4 \%$ in the Taiwanese population, a prevalence inbetween the Asian population studied by Suzuki and Harano.

Different methodologies to determine the prevalence of WED/RLS in diverse populations of women reveal it to be more prevalent during pregnancy (up to $34 \%$ ). Overall, the incidence of WED/RLS increases from the first to the third trimester $[19,21,25,28]$ and, in most cases, resolves quickly after delivery [18, 22, 24, 26, 28].

The true prevalence of PLMs during pregnancy in women who suffer from WED/RLS is unknown, but has been shown to be increased. Two articles were identified in PubMed that addressed PLMs and pregnancy. 
Table 1. Prevalence of WED/RLS During Pregnancy

\begin{tabular}{|c|c|c|c|c|}
\hline Year & Methods & Location & $\mathbf{N}$ & Prevalence in \% \\
\hline 2012 Chen et al. [16] & $\begin{array}{l}\text { Face to face interviews on admission to hospital with } \\
\text { questionnaires: } 4 \text { IRLSSG } 2003 \& \text { Johns Hopkins RLS } \\
\text { Severity Rating Scale; f/u } 2 \text { months PP; one neurologist } \\
\text { reviewed all; distinguished chronic vs. transient RLS }\end{array}$ & Taiwan & 461 & $\begin{array}{c}27 \% \text { chronic } \\
1 \Delta=8 \% \\
72.9 \% \text { transient } \\
3 \Delta=54 \% \\
10.4 \text { overall }\end{array}$ \\
\hline 2011 Balendaran et al. [17] & $\begin{array}{l}\text { Case-control; questionnaires administered to women in } 3 \Delta \\
\text { waiting for OB appointments; } 4 \text { IRLSSG } 2003+\text { symptom } \\
\text { description; no interview mentioned }\end{array}$ & $\mathrm{AU} / \mathrm{NZ}$ & 211 & 22.5 \\
\hline 2011 Uglane et al. [18] & $\begin{array}{l}\text { Questionnaires administered in hospital } 2-3^{\text {rd }} \mathrm{PP} \text { day; } 4 \\
\text { IRLSSG 2003; no interview mentioned }\end{array}$ & Norway & 251 & 34 \\
\hline 2010 Facco et al. $[19]$ & $\begin{array}{l}\text { Nulliparous women initially enrolled between 6-20 weeks } \\
\text { and follow-up 28-40 weeks; } 4 \text { IRLSSG 2003; self- } \\
\text { administered questionnaire }\end{array}$ & US & 189 & $\begin{array}{l}1 \Delta-17.5 \\
3 \Delta-32.2\end{array}$ \\
\hline 2010 Neau et al. [20] & $\begin{array}{c}\text { Cross-sectional; } 4 \text { IRLSSG } 2003+\text { symptom description; } \\
\text { self-administered questionnaire } 3 \Delta\end{array}$ & France & 186 & 32 \\
\hline 2010 Alves et al. [21] & Interview in $1 \Delta, 2 \Delta, 3 \Delta ; 4$ IRLSSG 2003 & Brazil & 524 & $\begin{array}{c}1 \Delta-5.6 \\
2 \Delta-43.7 \\
3 \Delta-50.3 \\
13.5 \text { overall }\end{array}$ \\
\hline 2010 Ismailogullari et al. [22] & $\begin{array}{c}\text { Interviews using surveys at delivery and } 6 \text { months PP; } 4 \\
\text { IRLSSG } 2003\end{array}$ & Turkey & $\begin{array}{c}983 \\
\text { power met }\end{array}$ & 10.5 \\
\hline 2009 Tunc et al. [23] & Interviews in clinic 16-36 weeks gestation; 4 IRLSSG 2003 & Turkey & 146 & 26.02 \\
\hline 2009 Sikandar et al. [24] & Interviews within 3 days PP; 4 IRLSSG 2003 & Pakistan & 271 & 30 \\
\hline 2008 Harano et al. [25] & $\begin{array}{l}\text { Self-administered questionnaires sent to clinics for women to } \\
\text { complete; } 4 \text { IRLSSG } 2003\end{array}$ & Japan & 19,441 & $\begin{array}{l}1 \Delta-1.6 \\
2 \Delta-2.3 \\
3 \Delta-3.5 \\
2.9 \text { overall }\end{array}$ \\
\hline 2004 Manconi et al. [26] & $\begin{array}{l}\text { Interviews at delivery and telephone interviews 1,3,6 months } \\
\text { PP; } 4 \text { IRLSSG } 1995\end{array}$ & Italy & 642 & 26 \\
\hline 2003 Suzuki et al. [27] & $\begin{array}{l}\text { Self-administered questionnaires; } 1 \text { IRLSSG } 1995 \text { criterion } \\
\text { worded as, 7. Is your sleep interrupted by a sensation of } \\
\text { "insects running across your skin" or hot flashes inside your } \\
\text { legs after you go to bed at night? }\end{array}$ & Japan & 16,528 & 19.9 \\
\hline 2001 Lee et al. [28] & $\begin{array}{l}\text { Prospective; preconception, } 1 \Delta, 2 \Delta, 3 \Delta ; 3 \text { items for } \\
\text { secondary analysis were included for incidence within past } \\
\text { week: 1)"arms or legs jerking as your fell asleep"; } 2 \text { ) } \\
\text { "restless legs as you fell asleep"; } 3 \text { ) "awakened from sleep } \\
\text { with leg cramps"; no interviewmentioned }\end{array}$ & US & 30 & $\begin{array}{l}\text { Preconception-0 } \\
\begin{array}{l}1 \Delta-12.5 \\
2 \Delta-18 \\
3 \Delta-23 \\
1 \text { mo PP- } 3\end{array}\end{array}$ \\
\hline 1988 Goodman et al. [29] & $\begin{array}{l}\text { Interview at 32-34 weeks gestation; telephone or mail follow- } \\
\text { up } 4 \text { weeks PP }\end{array}$ & England & 500 & 19 \\
\hline 1960 Ekbom [30] & Personal clinic cases including men and women & Sweden & $\begin{array}{l}175 \\
\text { how many } \\
\text { pregnant } \\
\text { not stated }\end{array}$ & $24($ if iron $<60 \mathrm{ug} / \mathrm{dL})$ \\
\hline 1945 Ekbom [31] & Interview & Sweden & 486 & 11.3 \\
\hline
\end{tabular}

Abbreviations: $1 \Delta$ : first trimester of pregnancy; $2 \Delta$ : second trimester of pregnancy; $3 \Delta$ : third trimester of pregnancy; PP: postpartum.

2003 IRLSSG Criteria: a. Desire to move the extremities usually associated with discomfort or disagreeable sensations in the extremities. b. Motor Restlessness-patients move to relieve the discomfort, for example walking, or to provide a counter-stimulus to relieve the discomfort, for example, rubbing the legs. c. Symptoms are worse at rest with at least temporary relief by activity. d. Symptoms are worse later in the day or at night [3].

1995 IRLSSG Criteria: (a) desire to move the extremities, often associated with paresthesias/ dysesthesias; (b) motor restlessness; (c) worsening of symptoms at rest with at least temporary relief by activity, and (d) worsening of symptoms in the evening or night [32]. 
Nikkola et al. (1996) studied nocturnal breathing patterns and oxygen saturation in women with multiple gestations [35]. Four of the 10 participants had WED/RLS. On polysomnography they found a PLM index of 3.7 to 49.7 , but this was not correlated with those who did or did not have WED/RLS. Dzaja et al. (2009) enrolled nine control subjects and ten women with WED/RLS and sought to establish a relationship between hormonal changes and WED/RLS symptomatology. WED/RLS sufferers had more PLMs before and after delivery, although the incidence decreased rapidly during the postpartum period. Group effect was statistically significant during wake and Stage 1 sleep $\left(\mathrm{F}_{1,13}=4.8, \mathrm{P}<0.05 ; \mathrm{F}_{1,13}=8.43, \mathrm{p}<0.05\right)$ [36].

The lack of standardization in data collection and reporting offers but a mere snap shot of the prevalence of WED/RLS and PLMs in pregnant and postpartum populations. The ideal study would enroll women in the first trimester, follow them into the second and third trimesters, and through the postpartum period, correlating symptoms with specific laboratory results and the presence or absence of PLMs. Women would be interviewed by a clinician knowledgeable about WED/RLS. The interviewer would be able to identify disorders that mimic WED/RLS and compile a comprehensive differential diagnosis. Until such a study has been conducted with diverse populations of pregnant women, the incidence of WED/RLS across all trimesters is, depending upon ethnicity, 2.9-34\%. At best, it can be stated that up to one out of three women will be affected by WED/RLS, with or without PLMs, during pregnancy.

Prospective, multi-center studies could help reveal the true incidence of WED/RLS during pregnancy. In the US, 4.3 million women give birth each year. If up to one out of every three women can be affected, over one million pregnant women may experience WED/RLS symptoms. Clinicians can diagnose and treat to mitigate the adverse consequences of disrupted sleep such as decreased daytime alertness and performance.

\section{PROPOSED ETIOLOGIES FOR WED/RLS}

Proposed etiologies for WED/RLS include: 1) genetic predisposition; 2) metabolic abnormalities (especially involving iron or folate homeostasis), 3) dopamine dysfunction; and 4) hormonal changes. Although the incidence of WED/RLS is increased during pregnancy, there is a paucity of research to explain the exact pathophysiologic mechanism that is the same as, or different from, the nonpregnant state. At best it can be said that up to $15 \%$ of pregnant women will enter pregnancy with pre-existing WED/RLS and the rest will develop new-onset WED/RLS by the third trimester.

\section{Genetic Predisposition}

An autosomal dominant trait has been identified [37-44]. Given that $40 \%$ of WED/RLS sufferers have a positive family history, it is imperative the clinician asks about symptoms in family members $[45,46]$.

\section{Iron or Folate Homeostasis}

An adequate amount of iron store dsystemically appears to be necessary to cross the blood brain barrier. Production of dopamine is iron dependent, and, for individuals with
WED/RLS, when the ferritin level falls below $50 \mathrm{mcg} / \mathrm{L}$, symptoms appear or worsen [47-50].

During the third trimester the fetus is growing and in need of maternal iron stores as it prepares for extrauterine life. Women who are at risk for WED/RLS are at a greater risk to develop symptoms as their iron stores are depleted; it makes sense that up to $34 \%$ of women may develop newonset WED/RLS.

One small study by Lee et al. (2001) correlated low serum folate levels with an increase in bedtime WED/RLS symptoms during the third trimester $(\mathrm{N}=40 ; \mathrm{WED} / \mathrm{RLS}=7$; $\mathrm{r}=-.44, \mathrm{p}=0.016)$ [28]. The difference between folate levels for those women with and without WED/RLS was statistically significant $(\mathrm{t}=2.4, \quad \mathrm{p}=0.03 ; \quad \mathrm{WED} / \mathrm{RLS}$ $14.9 \pm 11.8 \mathrm{ng} / \mathrm{ml}$ vs. control $18.6 \pm 16.2 \mathrm{ng} / \mathrm{ml})$. A minimum of $400 \mathrm{mcg}$ of folic acid is recommended for all women of reproductive age and throughout pregnancy. Women who suffer from WED/RLS should be encouraged to take a daily prenatal vitamin with $800-1000 \mathrm{mcg}$ of folic acid.

\section{Dopamine Dysfunction}

Dopamine is a neurotransmitter produced by the substantia nigra in the basal ganglia of the central nervous system and is necessary for coordinated and smooth functioning of muscle activity. A dopamine deficiency in individuals susceptible to WED/RLS is one hypothesis for the symptoms [51].

Normally within a 24 hour period and during the nighttime hours, an individual will experience a drop in serum iron level by up to $40-60 \%$ and a decrease in dopamine production. For the WED/RLS sufferer, this circadian drop in both iron and dopamine heralds the onset of symptoms. It is hypothesized that the decrease in serum iron disallows production of tyrosine hydroxylase in the central nervous system, a necessary enzymatic step in the production of dopamine. Decreased nighttime dopamine can lead to the dysethesias experienced by WED/RLS sufferers [51-54]. A circadian drop in iron and dopamine [55] may offer a reasonable hypothesis for explaining to women why their symptoms begin in the early evening and continue throughout the night.

\section{Hormonal Changes}

It is well known that placental hormones, especially estrogen, increase throughout pregnancy and decline after delivery. Recently, estradiol levels were noted to be elevated in pregnancies complicated by WED/RLS [36]. It is possible that the inhibitory effects of estradiol on dopaminergic systems [56, 57] may be associated with the higher prevalence of RLS in the third trimester and decline after delivery; however, much research is still needed to better clarify this association.

\section{DIAGNOSIS}

As with many clinical conditions, the most important means of diagnosing WED/RLS is through a detailed history and physical examination. The history should focus on the symptoms of WED/RLS, the timing of symptoms, the parts of the body affected, and effects on sleep and daytime 
Table 2. 10 Commandments of Sleep Hygiene for Adults

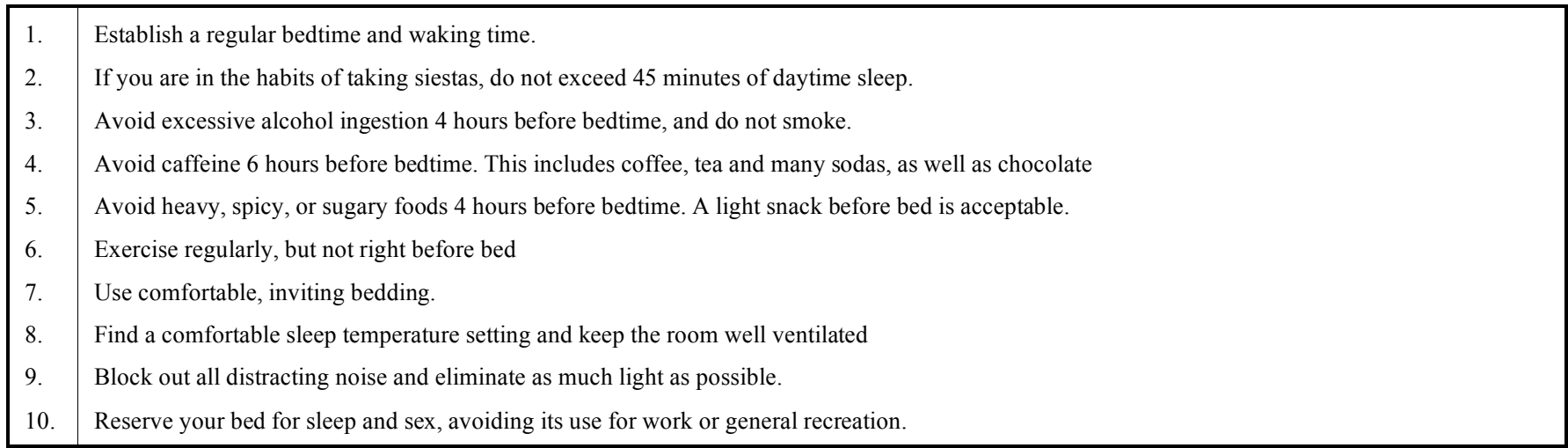

World Association of Sleep Medicine (WASM) http://www.worldsleepday.org/274/ [retrieved 9/8/2012).

functioning. Symptoms during pregnancy are essentially the same as those of non-gravid states.

Past medical, family, and drug history should be thoroughly reviewed to evaluate for other causes of WED/RLS. Anemia, renal failure, and thyroid dysfunction are known secondary causes of WED/RLS and are also seen in pregnancy. Antidopaminergic medications (e.g., metoclopramide), antihistamines (e.g., diphenhydramine), decongestants, tricyclic antidepressants, selective serotonin reuptake inhibitors, beta-blockers, lithium, caffeine, smoking, and alcohol are notorious for exacerbating WED/RLS.

The physical examination should include a complete neurological evaluation, especially of the lower extremities, to exclude neuropathies and vascular disorders that may resemble WED/RLS ("mimics"). Often, the physical examination is normal.

Laboratory work-up may include an assessment of iron stores, folic acid levels, vitamin B12 levels, thyroid function, and a metabolic panel. Evaluation of iron stores should include a complete blood count (CBC), serum ferritin, and iron saturation. Serum ferritin levels below $50 \mathrm{mcg} / \mathrm{L}$ have been associated with symptoms of WED/RLS and PLMs. Polysomnography is neither required nor recommended for the diagnosis of WED/RLS.

\section{Differential Diagnoses}

WED/RLS "mimics" include, but are not limited to, nocturnal leg cramps, nerve impingement, electrolyte imbalance, diabetic neuropathy, radiculopathy, claudication from premature peripheral arterial disease which affects $1 \%$ women $<35$ years old (especially with Type 2 Diabetes), severe lordosis, and post-thrombotic pain (previous deep vein thrombosis). Certain medications, including antibiotics, lipid-lowering agents which some women may have been taking prior to pregnancy, and non-steroidals, can all contribute to muscle weakness or dyskinesias [58-62].

\section{TREATMENT}

Treatment modalities for WED/RLS during pregnancy include behavioral strategies, as well as pharmacological interventions. Due to potential adverse drug effects on the fetus during pregnancy, behavioral interventions are preferred over pharmacologic interventions. However, pharmacologic therapy might be required, should not be withheld, and treatment should be individualized to the woman.

\section{Behavioral Interventions}

The first step in treatment involves removing potential aggravators of WED/RLS. These include: sleep deprivation, caffeine, alcohol, smoking and discontinuing medications that may worsen symptoms (see DIAGNOSIS). Although there is little evidence that Sleep Hygiene alone helps, the "10 Commandments of Sleep" are good, solid principles (see Table 2). Improving sleep hygiene by having a set bedtime and wake time, as well as not spending an excessive amount of time in bed, is recommended [55, 63]. Moderate daytime activity, limiting nighttime exercise, relaxation techniques (warm baths, leg vibration, massage, acupuncture), and enhanced external counterpulsion, such as pneumatic compression devices [64], have all been reported to relieve symptoms.

\section{Education}

Education about WED/RLS for the woman and her family members needs to be discussed to promote safe care and restorative sleep. Reassurance she and up to one out of every three pregnant women may develop WED/RLS symptoms is essential so she does not feel alone. Reassurance that symptoms abate by three months post partum offers hope. The woman may have a sense of control over the symptoms if she commits to iron repletion via a high iron diet and supplements if her ferrit in level is $<50$ $\mathrm{mcg} / \mathrm{L}$.

Once a diagnosis of WED/RLS has been made, communication between providers (physicians, advanced practice nurses, physicians' assistants) is essential for continuity of care. The treatment plan needs to be explicitly written, with WED/RLS added as a diagnosis to the problem list. Determining compliance and adequacy of treatment at each visit should be documented.

\section{Iron}

In women with WED/RLS symptoms, the complete blood count (CBC), especially the hemoglobin and hematocrit, may be normal while the serum ferrit in is $<50$ $\mathrm{mcg} / \mathrm{L}$ and the iron saturation $<20 \%$. At this point, iron repletion should be initiated and the $\mathrm{CBC}$, ferritin and iron 
Table 3. Iron Preparations

\begin{tabular}{|c|c|c|}
\hline Iron Preparation & Total Iron & Elemental Iron \\
\hline \hline Ferrous gluconate & $1000 \mathrm{mg}(12 \%$ elemental iron $)=$ & $120 \mathrm{mg}$ \\
\hline Ferrous sulfate $325 \mathrm{mg}$ TID $=200 \mathrm{mg} / \mathrm{day}$ & $1000 \mathrm{mg}(20 \%$ elemental iron $)=$ & $200 \mathrm{mg}$ \\
\hline Ferrous bisglycinate & Similar to ferrous sulfate & Easier on GI tract \\
\hline Ferrous sulfate exsiccated & $1000 \mathrm{mg}(32 \%$ elemental iron $)=$ & $320 \mathrm{mg}$ \\
\hline Ferrous fumarate & $1000 \mathrm{mg}(33 \%$ elemental iron $)=$ & $330 \mathrm{mg}$ \\
\hline
\end{tabular}

UL $45 \mathrm{mg} /$ day for supplementation; does not apply to people under medical supervision for iron deficiency. Iron deficiency anemia: elemental iron 50-65 mg three times a day (TID).

Table 4. FDA Categories of Drugs During Pregnancy

\begin{tabular}{|c|c|}
\hline Pregnancy Category & Description \\
\hline Category A & $\begin{array}{l}\text { Adequate and well-controlled human studies have failed to demonstrate a risk to the fetus in the first trimester of pregnancy } \\
\text { (and there is no evidence of risk in later trimesters). }\end{array}$ \\
\hline Category B & $\begin{array}{l}\text { Animal reproduction studies have failed to demonstrate a risk to the fetus and there are no adequate and well-controlled } \\
\text { studies in pregnant women OR Animal studies have shown an adverse effect, but adequate and well-controlled studies in } \\
\text { pregnant women have failed to demonstrate a risk to the fetus in any trimester. }\end{array}$ \\
\hline Category D & $\begin{array}{l}\text { There is positive evidence of human fetal risk based on adverse reaction data from investigational or marketing experience or } \\
\text { studies in humans, but potential benefits may warrant use of the drug in pregnant women despite potential risks. }\end{array}$ \\
\hline Category X & $\begin{array}{l}\text { Studies in animals or humans have demonstrated fetal abnormalities and/or there is positive evidence of human fetal risk } \\
\text { based on adverse reaction data from investigational or marketing experience, and the risks involved in use of the drug in } \\
\text { pregnant women clearly outweigh potential benefits. }\end{array}$ \\
\hline
\end{tabular}

saturation levels rechecked in one, two and three months. Iron repletion can be discontinued when WED/RLS symptoms abate, the serum ferritin is $>50 \mathrm{mcg} / \mathrm{L}$ and the iron saturation is $>20 \%$. The complete metabolic panel might reveal liver or kidney disease, or an electrolyte imbalance. The latter will not be addressed.

Iron repletion may take the form of ferrous sulfate 325 mg plus Vitamin C 250-500 mg three times a day, on an empty stomach. Three tablets of ferrous sulfate per day provide $200 \mathrm{mg}$ of elemental iron. Although it is the most cost effective treatment, ferrous sulfate may cause severe constipation during pregnancy. An alternative would be SlowFe $^{\circledR}$ with Vitamin C 250-500 twice daily, or the addition of a stool softener such as Colace ${ }^{\circledR} 100 \mathrm{mg}$ twice daily. Table 3 compares iron products available in the US market and the amount of elemental iron in each.

Iron repletion should be stopped immediately if hemochromotosis is evident. Diagnosis is made by elevated liver enzymes, bronze color of the skin, or iron (transferrin) saturation $>50 \%$ [59].

\section{Folate}

Evaluation of a folate level should be considered for WED/RLS sufferers. It is prudent to encourage all pregnant women to take $800-1000 \mathrm{mcg}$ of folic acid prior to conception and throughout pregnancy to decrease the incidence of neural tube defects, as well as help with
WED/RLS symptoms [65]. This dosage is available in all over the counter and prescription prenatal vitamins.

\section{Magnesium}

In pregnancy, magnesium is Category $\mathrm{C}$ (See Table 4). However, 250 to $800 \mathrm{mg}$ of elemental magnesium per day, in the form of magnesium citrate, 100 to $250 \mathrm{mg}$ at bedtime, may help alleviate WED/RLS symptoms, especially if PLMs are present [66, 67]. Magnesium may stabilize cellular membrane transmission, decreasing WED/RLS and PLMs symptoms.

\section{PHARMACOLOGIC AGENTS}

Theoretically, all of the drug regimens used to treat WED/RLS should be effective in the treatment of pregnancy-related WED/RLS. These include dopaminergics and dopamineagonists, benzodiazepines, opiates, antiepileptics, sympatholytics, and vitamins and minerals. However, many of these drugs are Food and Drug Administration (FDA) Pregnancy Category C, D, or X, the latter two being contraindicated during pregnancy (see Table 5) $[68,69]$.

When the woman's symptoms cannot be controlled by behavioral interventions, or until the woman is iron repleted, pharmacologic modalities may be required. This could help mitigate the effects of disrupted sleep such as decreased daytime attention and performance. A discussion of the 
Table 5. Pharmacologic Treatment of WED/RLS during Pregnancy [65, 66]

\begin{tabular}{|c|c|c|}
\hline Agent & Start Dosemg/Day & Pregnancy Category \\
\hline$\frac{\text { Dopaminergics }}{\text { carbidopa/levodopa }}$ & $25 / 100$, or $25 / 100$ controlled release & $\mathrm{C}^{* * *}$ \\
\hline \multicolumn{3}{|l|}{$\underline{\text { Anti-convulsants }}$} \\
\hline 1. gabapentin & 1.100 or $300 \mathrm{mg}$ & $\mathrm{C}^{* * *}$ \\
\hline 2. gabapentin enacarbil & 2. no literature & \\
\hline \multicolumn{3}{|l|}{ Dopamine agonists } \\
\hline 1. ropinirole & 1. $0.25 \mathrm{mg}$ to $4 \mathrm{mg}$ & $\mathrm{C}^{*}, * *$ \\
\hline 2. pramipexole & 2. $0.125 \mathrm{mg}$ to $.25 \mathrm{mg}$ & $\mathrm{C}^{*}, * *$ \\
\hline \multicolumn{3}{|l|}{$\underline{\text { Opioids }}$} \\
\hline codeine & $15-30(\max 120)$ & $\mathrm{C}^{*}$ caution with rapid metabolizers \\
\hline oxycodone & 5 to $10(\max 20)$, or $10 \mathrm{mg} \mathrm{CR}(\max 30)$ & $\mathrm{B}$ \\
\hline hydrocodone & 5 to $10(\max 30)$ & $\mathrm{C}$ \\
\hline tramadol & 50 to $100(\max 400)$ & $\mathrm{C}$ \\
\hline 5. methadone & 5 to $10(\max 40)$ & $\mathrm{B}$ \\
\hline \multicolumn{3}{|l|}{$\underline{\text { Sedative }}$} \\
\hline 1. zolpidem & $1.10 \mathrm{mg}$ & $\mathrm{B}$ \\
\hline 2. benzodiazepines; clonazepam & 2. $0.5-2 \mathrm{mg}$ & D - wean in $3 \Delta$ to prevent "floppy baby syndrome" \\
\hline \multicolumn{3}{|l|}{ Antihypertensive/CNS analgesic } \\
\hline clonidine & $0.1 \mathrm{mg}$ & $\mathrm{C}$ \\
\hline \multicolumn{3}{|l|}{ Beta-Blocker } \\
\hline propanolol & $10 \mathrm{mg}$ up to $80 \mathrm{mg}$ & $\mathrm{C} ; \mathrm{D}$ in $2 \& 3 \Delta$ \\
\hline \multicolumn{3}{|l|}{$\underline{\text { Other }}$} \\
\hline cannabis & Not recommended & $\mathrm{X}$ \\
\hline
\end{tabular}

*use after $1^{\text {st }} \Delta ; * *$ not during lactation; ***no studies in pregnancy \& lactation.

Abbreviations: $2 \Delta$ : second trimester of pregnancy; $3 \Delta$ : third trimester of pregnancy.

appropriate use of medications should be initiated with the woman.

\section{OPIOIDS}

Opioids for the treatment of WED/RLS are not FDA approved, but used off-label. In selected women, opioids may be the safest option duringthe third trimester, as oxycodone is in currently Pregnancy Category B [68-72]. In the first trimester opioids should be used with caution. A retrospective study of over 17,000 women compels an association between opioid use and congenital anomalies [73]. Data collected could have been contaminated by polypharmaceutical use. When used appropriately, there is little potential for abuse [65]. Opioids should be used cautiously as the estimated due date approaches to prevent neonatal withdrawal syndrome. The newborn's clinician should be made aware of medications taken by the mother.

Opioids bind to mu receptors in the pain modulating areas of the central nervous system and dorsal horn of the spinal column [74]. Opioids block WED/RLS sensations. After discussion of the risks and benefits, the clinician may request the woman sign aconsent form for opioid treatment and meticulously monitor use at each obstetric visit. Due to the plethora of hepatic enzymes that metabolize opiates, if one opiate does not decrease WED/RLS symptoms, another could be tried.Special attention should be paid to the woman given an opiate, who may be a "rapid metabolizer", and overly sensitive to the depressant effects of the medication [75].

\section{Dopamine Agonists}

Dopamine-agonists are category $\mathrm{C}$, but increase fetal wastage in the first trimester and decrease lactation postpartum $[68,69]$. If used, they should be considered after the first trimester, and not during lactation, or at least not until mature breast milk and a definitive breast feeding schedule has been established. Dopaminergic agents should be taken one to three hours before bedtime; they work by mimicking dopamine in the brain. There is a risk of augmentation and rebound with prolonged use [74].

\section{Benzodiazepines}

Benzodiazepines are Pregnancy Category D during pregnancy and lactationdue to potential teratogenicity, "floppy baby syndrome", and depression of the newborn's central nervous system. Clonazepam may be the only helpful medication for a pregnant woman, and if needed, should be confined to the second trimester with the dosing tapered in 
the third trimester as the estimated due date approaches. Benzodiazepines work by increasing the amount of gamma amino-butyric acid, a calming neurotransmitter in the brain [74].

\section{DISCUSSION}

The incidence of WED/RLS in women is twice as high as in men. During pregnancy, WED/RLS can affect up to one in three women. Given the daytime consequences of disordered sleep (excessive daytime sleepiness, irritability, cognitive impairment), clinicians should screen and treat pregnant women who present with WED/RLS symptoms. If behavioral interventions do not help, the clinician should first try iron repletion if the ferritin level is $<50 \mathrm{mcg} / \mathrm{L}$, and/or consider low dose opioid therapy at bedtime.

\section{CONFLICT OF INTEREST}

The authors confirm that this article content has no conflicts of interest.

\section{ACKNOWLEDGEMENT}

Declared none.

\section{REFERENCES}

[1] Yoakum R. Night walkers: Do your legs seem to have a life of their own? Your torment has a name. Mod Maturity 1994, 55: 82-4.

[2] RLS Name Change. Willis-Ekbom Disease. Nightwalkers. A publication of the restless legs syndrome foundation. 2011Spring, [cited: 2012 March 29]. Available from: http://www.rls.org/Document.Doc?id=2128

[3] Allen RP, Picchietti D, Hening WA, Trenkwalder C, Walters AS, Montplaisi J. Restless legs syndrome: Diagnostic criteria, special considerations, and epidemiology. A report from the restless legs syndrome diagnosis and epidemiology workshop at the National Institutes of Health. Sleep Med 2003, 4:101-19.

[4] Nosology Committee. The International Classification of Sleep Disorders. $2^{\text {nd }}$ ed. Westchester, IL: American Academy of Sleep Medicine 2006.

[5] Zucconi M, Ferri R, Allen RP, et al. The official World Association of Sleep Medicine (WASM) standards for recording and scoring periodic leg movements in sleep (PLMS) and wakefulness (PLMW) developed in collaboration with a task force from the International Restless Legs Syndrome Study Group (IRLSSG). Sleep Med 2006, 7(2); 175-83.

[6] Coleman RM. Periodic movements in sleep (nocturnal myoclonus) and restless legs syndrome. In : Guilleminault C, Ed. Sleeping and Waking Disorders: Indications and Techniques. Menlo Park, CA: Addison-Wesley 1982; pp.265-95.

[7] Willis T. The London practice of physick. London: Bassett and Crooke 1685; p.404.

[8] Konofal E, Karroum E, Montplaisir J, Derenne JP, Arnulf I. Two early descriptions of restless legs syndrome and periodic leg movements by Boissier de Sauvages (1763) and Gilles de la Tourette (1898). Sleep Med 2009; 10(5): 586-91.

[9] Wittmaack T. Pathologie und therapie der sensibilitatneurosen Leipzig: E Schafer, 1861; p. 459.

[10] Beard GM. A practical treatise on nervous exhaustion. New York, NY: William Wood 1880; pp.41-2.

[11] Bing R. Lehrbruch der Nervenkrakheiten. Berlin: Karger 1913; p.522.

[12] Oppenheim H. Lehrbruch der nervenkrakheiten. Berlin: Karger 1923 ; p.1774.

[13] Mussio Fournier JC, Kawak F. Rev Neurology Paris 1947; 79 (5): 337-41.

[14] Ekbom KA. Restless legs. Acta Med Scand 1945; 158: 1-123.

[15] Phillips B, Young T, Finn L, et al. Epidemiology of restless legs syndrome in adults. Arch Int Med 2000; 160(14): 2137-41.

[16] Chen P-H, Liou K-C, Chen C-P, Cheng S-J. Risk factors and prevalence rate of restless legs syndrome among pregnant women in Taiwan. Sleep Med 2012. Available from: http://dx.doi.org/10.1016/j.sleep.2012.06.008

[17] Balendran J, Champion D, Jaaniste T, Welsh A. A common sleep disorder in pregnancy: Restless legs syndrome and its predictors. Aust N Z J Obstet Gynaecol 2011; 51(3): 262-4.

[18] Uglane MT, Westad S, BackeB. Restless legs syndrome in pregnancy is a frequent disorder with a good prognosis. Acta Obstet Gynecol Scand 2011; 90(9): 1046-8.

[19] Facco FL, Kramer J, Ho KH, Zee PC, Grobman WA. Sleep disturbances in pregnancy. Obstet Gynecol 2010, 115(1): 77-83.

[20] Neau JP, Marion P, Mathis S, et al. Restless legs syndrome and pregnancy: Follow-up of pregnant women before and after delivery. Eur Neurology 2010; 64(6): 361-6.

[21] Galdino Alves DA, de Carvalho LB, de Morais JF, do Prado GF. Restless legs syndrome during pregnancy in Brazilian women. Sleep Med 2010; 11(10):1049-54.

[22] Ismailogullari S, Ozturk A, Mazicioglu MM, Serin S, Gultekin M, Aksu M. Restless legs syndrome and pregnancy in Kayseri, Turkey: A hospital based survey. Sleep Biol Rhythms 2010; $8(2): 137-43$.

[23] Tunç T, Karadağ YS, Doğulu F, Inan LE. Predisposing factors of restless legs syndrome in pregnancy. Mov Disord 2009; 22(5): 62731 .

[24] Sikandar R, Khealani BA, Wasay M. Predictors of restless legs syndrome in pregnancy: A hospital based cross sectional survey from Pakistan. Sleep Med 2009; 10: 676-8.

[25] Harano S, Hida T, Kaneita Y, et al. Prevalence of restless legs syndrome with pregnancy and relationship with sleep disorders in the Japanese large population. Sleep Biol Rhythms 2008; 6(2): $102-$ 09 .

[26] Manconi M, Govoni V, De Vito A, et al. Restless legs syndrome and pregnancy. Neurology 2004; 63(6):1065-9

[27] Suzuki K, Ohida T, Sone T, et al. The prevalence of restless legs syndrome among pregnant women in Japan and the relationship between restless legs syndrome and sleep problems. Sleep 2003; 26(6): 673-7.

[28] Lee KA, Zaffke ME, Baratte-Beebe K. Restless legs syndrome and sleep disturbance during pregnancy: the role of folate and iron. J Womens Health Gend Based Med 2001; 10(4): 335-41.

[29] Goodman JD, Brodie C, Ayida GA. Restless legs syndrome in pregnancy. Br Med J 1988; 297(6656):1101-2.

[30] Ekbom KA. Restless legs syndrome. Neurology 1960; 10: 868-73

[31] Ekbom KA. Restless legs: a clinical study. Acta Med Scand 1945; 158: $1-123$

[32] Walters AS. Toward a better definition of the restless legs syndrome. The International Restless Legs Syndrome Study Group. Mov Disord 1995; 10(5): 634-42.

[33] Inami Y, Horiguchi J, Innami T, et al. An epidemiological study on sleep-wake disorders in the elderly. Clin Psychiatry 1990; 32: 521 6.

[34] Horiguchi J, Sasaki A, Inami Y, et al. An epidemiological study on trait of sleep-wake complaints in the aged comparing with the younger subjects. Clin Psychiatry 1991; 33: 403-9.

[35] Nikkola E, Ekblad, U, Ekholm E, Hannu Mikola H, Polo O. Sleep in multiple pregnancy: Breathing patterns, oxygenation, and periodic leg movements. Am J Obstet Gynecol 1996; 174(5): 1622 5.

[36] Dzaja A, Wehrle R, Lancel M, Pollmacher T. Elevated estradiol plasma levels in women with restless legs during pregnancy. Sleep 2009; 32: 169-74.

[37] Yeh P, Walters AS, Tsuang JW. Restless legs syndrome: a comprehensive overview on its epidemiology, risk factors, and treatment. Sleep Breath 2011; 1-21.

[38] Pichler I, Marroni F, Volpato CB, et al. Linkage analysis identifies a novel locus for restless legs syndrome on chromosome $2 \mathrm{q}$ in a South Tyrolean population isolate. Am J Hum Genet 2006; 79: 716.

[39] Chen S, Ondo WG, Rao S, et al. Genomewide linkage scan identifies a novel susceptibility locus for restless legs syndrome on chromosome 9p. Am J Hum Genet 2004; 74: 876.

[40] Lohmann-Hedrich K, Neumann A, Kleensang A, et al. Evidence for linkage of restless legs syndrome to chromosome 9p: are there two distinct loci? Neurology 2008; 70: 686.

[41] Desautels A, Turecki G, Montplaisir J, et al. Identification of a major susceptibility locus for restless legs syndrome on chromosome 12q. Am J Hum Genet 2001; 69: 1266. 
[42] Desautels A, Turecki G, Montplaisir J, et al. Restless legs syndrome: confirmation of linkage to chromosome $12 \mathrm{q}$, genetic heterogeneity, and evidence of complexity. Arch Neurology 2005; 62: 591 .

[43] Bonati MT, Ferini-Strambi L, Aridon P, et al. Autosomal dominant restless legs syndrome maps on chromosome 14q. Brain 2003; 126 : 1485.

[44] Levchenko A, Provost S, Montplaisir JY, et al. A novel autosomal dominant restless legs syndrome locus maps to chromosome 20p13. Neurology 2006; 67: 900.

[45] Hening W, Allen R, Earley C, et al. The treatment of restless legs syndrome and periodic limb movement disorder. An American Academy of Sleep Medicine Review. Sleep 1999; 22: 970.

[46] Montplaisir J, Boucher S, Poirier G, et al. Clinical, polysomnographic, and genetic characteristics of restless legs syndrome: a study of 133 patients diagnosed with new standard criteria. Mov Disord 1997; 12: 61

[47] Allen RP. Controversies and challenges in defining the etiology and pathophysiology of restless legs syndrome. Am J Med 2007; 120(1 suppl 1): S13-21.

[48] Connor JR, Wang XS, Patton SM, et al. Decreased transferrin receptor expression by neuromelanin cells in restless legs syndrome. Neurology 2004; 62: 1563-7.

[49] Sun ER, Chen CA, Ho G, Earley C, Allen RP. Iron and the restless legs syndrome. Sleep 1998; 21: 381-7.

[50] Earley C, Allen RP, Beard JL, Connor JR. Mini-review: Insight into the pathophysiology of restless legs syndrome. J Neurosci Res 2000; 62: 623-8.

[51] Clemens S, Rye D, Hochman S. Restless legs syndrome: revisiting the dopamine hypothesis from the spinal cord perspective. Neurology 2006; 67: 125.

[52] Earley CJ, Connor JR, Beard JL, Malecki EA, Epstein DK, Allen RP. Abnormalities in CSF concentrations of ferritin and transferrin in restless legs syndrome. Neurology 2000; 54(8): 1698-700.

[53] Earley CJ, Hyland K, Allen RP. CSF dopamine, serotonin, and biopterin metabolites in patients with restless legs syndrome. Mov Disord 2001; 16(1): 144-9

[54] Earley CJ, Hyland K, Richard P. Allen RP. Circadian changes in CSF dopaminergic measures in restless legs syndrome. Sleep Med 2006; 7(3): 263-8.

[55] Trenkwalder C, Hening WA, Walters AS, Campbell SS, Rahman K, Chokroverty S. Circadian rhythm of periodic limb movements and sensory symptoms of restless legs syndrome. Mov Disord 1999; 14:102-10

[56] Thompson TL, Certain ME. Estrogen mediated inhibition of dopamine transport in the striatum: regulation by $\mathrm{G}$ alpha i/o. Eur J Pharmacol 2005; 511: 121-6.

[57] Myers RE, Anderson LI, Dluzen DE. Estrogen, but not testosterone attenuates methamphetamine-evoked dopamine output from superfused striatal tissue of female and male mice. Neuropharmacology 2003; 44: 624-32.

[58] Marter A, Agruss JC. Solving the riddle of fibromyalgia: An evidence-based practice protocol for the advanced practice nurse. J Nurs Pract 2008; 4: 424-37.

[59] McPhee SJ, Papadakis MA, Tierney LM, Ed. Current medical diagnosis and treatment 2012. $51^{\text {st }}$ ed. New York: Lange Medical Books/ McGraw Hill, 2012.
[60] Leguizamon G, Igarzabal ML, Reece EA. Periconceptual care of women with diabetes. Obstet Gynecol Clin North Am 2007; 34: 225-39.

[61] Choudhury D, Ahmed Z. Drug-associated renal dysfunction and injury. Nat Clin Pract Nephrol 2006; 2: 80-91.

[62] National Heart, Lung, and Blood Institute Web site. NHLBI workshop on peripheral arterial disease (PAD): Developing a public awareness campaign. Meeting summary. USA: US Department of Health and Human Services, National Institutes of Health, National Heart, Lung and Blood Institute. Available from: www.nhlbi.nih.gov/health

[63] Hening W, Allen R, Earley C, Kushida C, Picchietti D, Silber M. The treatment of restless legs syndrome and periodic limb movement disorder. An American Academy of Sleep Medicine Review. Sleep 1999; 22: 970-99.

[64] Rajaram SS, Shanahan J, Ash C, Walters AS, Weisfogel G. Enhanced external counter pulsation (EECP) as a novel treatment for restless legs syndrome (RLS): A preliminary test of the vascular Neurologyogic hypothesis for RLS. Sleep Med 2005; 6: 101-6.

[65] CDC. CDC Grand Rounds: Additional opportunities to preven neural tube defects with folic acid fortification. Morb Mortal Wkly Rep 2010; 59(31): 980-4.

[66] Hornyak M, Voderholzer U, Hogagen F, Berger M, Riemann D Magnesium therapy for periodic leg movements-related insomnia and restless legs syndrome: An open pilot study. Sleep 1998; 21: 501-5.

[67] Rijsman RM, de Weerd AW. Secondary periodic limb movement disorder and restless legs syndrome. Sleep Med Rev1999; 3(2): 147-58.

[68] Briggs, GG, Freeman RK, Yaffe SJ. (2011-01-01). Drugs in pregnancy and lactation: A reference guide to fetal and neonata risk (Kindle Locations 2-5). Lippincott (Wolters Kluwer Health). Kindle Edition.

[69] MICROMEDEX 2.0® Subscriptions for University of Colorado Denver (Customer \#: 452960001). [cited 2012 March 31]. Available from: http://www-thomsonhc-com.hsl-ezproxy.ucdenver.edu/micromedex2/librarian/ND_T/evidencexpert/ND_PR/evid encexpert/CS/694357/ND_AppProdūct/evidencexpert/DUPLICATI ONSHIELDSYNC/7A0092/ND PG/evidencexpert/ND B/evidenc expert/ND_P/evidencexpert/PFActionId/pf.HomePage

[70] Phillips B. Movement disorders. A sleep specialist's perspective. Neurology 2004; 62(Suppl 2): S9-S16.

[71] Hening WA. Current guidelines and standards of practice for restless legs syndrome. Am J Med 2007; 120(1A): S22-7.

[72] Walters AS, Winkelmann J, Trenkwalder C, et al. Long-term follow-up on restless legs syndrome patients treated with opioids. Mov Disord 2001; 16(6): 1105-9.

[73] Broussard CS, Rasmussen SA, Reefhuis J, et al. Maternal treatment with opioid analgesics and risk for birth defects. Am J Obstet Gynecol 2011;204314.e1-11.

[74] King T, Brucker M, Eds. Pharmacology for women's health. Boston: Jones \& Bartlett, 2011.

[75] Kirchheiner J, Schmidt H, Tzvetkov M, et al. Pharmacokinetics of codeine and its metabolite morphine in ultra-rapid metabolizers due to CYP2D6 duplication. Pharmacogenomics J 2006; 7: 1-9.

(C) Hensley and Shamim-Uzzaman; Licensee Bentham Open.

This is an open access article licensed under the terms of the Creative Commons Attribution Non-Commercial License (http://creativecommons.org/licenses/by$\mathrm{nc} / 3.0 /$ ), which permits unrestricted, non-commercial use, distribution and reproduction in any medium, provided the work is properly cited 